and for the present be content with the knowledge of the fact, that one disease, whether artificially or spontancously generated, will often, not invarialily, supersede another." I aceept the whole of this passage as expressive of more than one important truth. "Not invariably" do medicines produce the effect here ascribed to them, is quite as much a truth as that they "often" do; as nature adopts different modes of relieving discase, so must the pliysician; and this leads me to my third division of dynamic treatment.

['T'o be continued.]

RULES FOR THE PERFORMANCE OF IRIDECTORY IN GLAUCOMA.

[Trinslated, with remarks, for the Boston Medical and Surgical Journnl, by Il_SKEx Derey, N.D.]

Maxy inquiries having been recently made of me as to the proper method of performing iridectomy in glaucoma, I fecl that I can do no better thian to state, in his own words, a few of the principles that Professor ron Gracfe has laid down for the guidance of others. I will merely premise that by "external incision" is meant the cut made hy the lance knife in piercing the sclerotic, and by "internal incision" the cut made at its emergence into the anterior chamber.

" 1 . The incisions must be disposed as excentrically as possible, so that the external incision be made in the sclerotic about half a line from the edge of the cornea, and the internal incision directly in the line of junction of the cornca and sclerotic. It is thus rendered possible to remore the iris up to its ciliary insertion, and it appear's that this is necessary to, and at any rate ensures, the result. Inasmuch, moreover, as the accompanying mydriasis narrows the width of the iris, any deviation of the internal incision from the periphery of the cornea would materially diminish the size of the excised portion.

"2. As large a piece of the iris as possible must be excised, on which account either a rery broad lance knife must be employed, or an ordinary one must be made to enter morc deeply. 'This operation is in this respect quite different from the usual one for artificial pupil, snch as would, for example, be performed in the case of a leucoma adhærens, where, as is well known, optical reasons cause us to prefer a pupil of small size. But the more extensive the glaucomatous process, the more marked the increase of intra-ocular pressure, the larger the portion of iris I recommend excising. The point to be selected for performing the operation is naturally immaterial. I generally excise the iris inwards; should, however, a regard for appearances dispose us to be especially scrupulous, the excision may he made upwards. The age of the patient, however, gencrally renders this consideration unnecessary, besides which I consider an opening in the iris made inwards of little consequence, and certainly hardly perceptible in dark eyes. The operation fur removing an upper portion of the iris is, moreover, inconvenient, 
and requires a more complete rotation of the bulb with the instrument used for fixation-a manœurre that might be prejudicial to an eye excessirely inflamed.

"3. Great care must be exercised in the eracuation of the aqueous humor, because in these cases a too sudden diminution of the intraocular pressure might cause extensire hæmorrhage not only among the decper tissues, but into the chambers of the eye. It is true that the relatively grcater pressure-maintained even after the evacuation of the aqueous humor-is a cause why such hæmorrhages should take place less frequently than in ordinary iritochoroiditis, with atrophy of the bulb; and, in fact, we rarcly find in glaucoma effusions so extensive and so obstinately resisting absorption as in the above-mentioned class of cases. On the other hand, however, there lies, in the nature of the disease, a strong predisposition to rupture of the vessels, whether caused by a direct implication of their walls, or by the preceding venous strangulation, I shall not undertake to say. I have already called repeated attention to the occurrence of retinal apoplexies, which fact alone should induce us to exercise foresight. While the aqueous humor is being evacuated, I am careful to exercise a slight compression with the finger on the bulb, and shortly after the operation I apply to the eye a compressive bandage, which, after a few hours, I carefully loosen.

"I have found no other special treatment necessary. Even in those cases where the operation was done at the period of the most acute inflammation, the symptoms of inflammation seemed to voluntarily disappear. An exception may, however, sometimes be made in such cases, and an antiphlogistic course of treatment pursued, in order to hasten the disappearance of the inflammatory symptoms. It is hardly necessary to add that such eyes must be longer guarded from light, and the common precautions more carefully followed than in ordinary cases of iridectomy."

One single point that has not been touched, in the foregoing observations, I think of sufficient importance to allude to. In most cases, as soon as the iris has been divided by the scissors, bleeding takes place into the anterior chamber. In order to avoid the protracted process of absorption, it is important that this blood should be removed before the wound is allowed to close; and this is readily effected by placing the point of a Daviel's scoop on the edge of the external incision, and gently pressing with its back against the sclerotic. The wound is thus made to open slightly, and the blood follows of itself. I have observed that von Graefe rarely neglects this precaution.

Von Graefe, Donders and Desmarres entrust the division of the iris to an assistant; Arlt, Bowman and Critchett perform this act themselves, and the two last-named gentlemen employ spring specula for the separation of the lids, and are thus enabled to perform every step of the operation themselves. Unless we have an assistant thoroughly familiar with the proceeding, the latter seems by far the 
better course, for no part of the operation dernands a quicker eyo or a steadier hand than the proper division of the iris. H. D.

\section{CASES IN COUNTRY PRACTICE.}

By John Ellis Brake, M.D., of Midnletown, Conn.

[Communicated for the Boston Medical and Surgical Journal.]

No. II.-Severe Wound of Hand and Wrist.

THE history of a simple cut in ordinary situations would certainly hardly be worth recording; and perhaps the following case may bo thought trivial; yet, even kecping in view some of the graver situations in which a surgeon, especially in the country, may be placed, I cannot but regard this case as presenting some features of difficulty.

G. S., a young man of 24 years, returning from the hay-ficld, in vaulting over a fence, caught the heel of his scythe, which he was carrying detached from the snathe, upon the top-rail. The blade, being thus drawn through the hand for its entire length, and pressed in by the weight of his body, inflicted a severe wound, which extended through everything, down to the integuments on the back of the wrist and the metacarpal bones, from thrce fourths of an inch above the pisiform bone, to the base of the first phalanx of the forefinger. The bones of the carpus were separated by the blade, and the hand fell apart, like the body of a fowl prepared for broiling. The patient was carricd to the nearest house-an isolated farmhouse, and before I could see him, had lost more blood than he could well spare. Althougl quite faint, the removal of the temporary bandages was attended (before the tourniquet was screwed tight enough to check it) by profuse hæmorrhage, and this of an embarrassing character. The bleeding seemed to be forward and backward, from the more superficial vessels, and upward, from between a mass of divided tendons and nerves, from the deeper arch. On consultation with a professional friend, whom I sent for, and who was my only reliable assistant, we decided to tie each divided vessel in succession, rather than to go above upon the main trunk. The doing of this was not rendered more easy or agreeable, by surrounding circumstances; the scene of action being a small bed-room, as warm as such an apartment could well be on a hot night in July, the same being crowded with sympathizing and perspiring neighbors. The best light that was obtainable was afforded by tallow candles, held by these neighbors. Notwithstanding various and annoying disappointments, we finally succeeded in ligaturing each divided vessel, including the ulnar, to the number of thirteen or more. The two parts of the hand were then brought together, and maintained in position, upon a curved splint, with water dressings. The patient, although very feeble for some time, from the excessive hæmorrhage, made, in the end, a good recovery, and has a very good use of his VOL. LXVI.-No. 12A 